\title{
Charismatic Technology
}

\author{
Morgan G. Ames \\ Intel Science and Technology Center for Social Computing \\ University of California, Irvine \\ charisma@morganya.org
}

\begin{abstract}
To explain the uncanny holding power that some technologies seem to have, this paper presents a theory of charisma as attached to technology. It uses the One Laptop per Child project as a case study for exploring the features, benefits, and pitfalls of charisma. It then contextualizes OLPC's charismatic power in the historical arc of other charismatic technologies, highlighting the enduring nature of charisma and the common themes on which the charisma of a century of technological progress rests. In closing, it discusses how scholars and practitioners in human-computer interaction might use the concept of charismatic technology in their own work.
\end{abstract}

\section{Author Keywords}

Charisma, childhood, education, history of technology, ideology, One Laptop per Child, religion, science and technology studies, technological determinism, utopianism.

\section{ACM Classification Keywords}

K.4.0. Computers in Society: general.

\section{INTRODUCTION}

Scholars have noted the holding power that some technologies seem to have - a power that goes beyond mere form or function to stimulate devotion, yearning, even fanaticism $[2,39,44,62]$. While Apple products, especially iPhones, are often held up as the most common example of this holding power $[11,31,37,40,52,56]$, it exists in various forms for many technologies, from sports cars to strollers.

This paper describes this holding power as charisma. Applying Weber's theory of charismatic authority [68] to objects, it presents a case study of a technology that was highly charismatic to its makers and supporters (and remains so to a devoted core): the One Laptop per Child (OLPC) project's "XO" laptop. With about two and a half million in use globally, OLPC's green-and-white XO remains a focal point for discourses about children, technology, and education, even a decade after its 2005 debut. This analysis explores the roots of the laptop's charisma and the important role that charisma played in OLPC's heady early days. It then reflects on the charismatic elements present in this project in

Copyright $\odot 2015$ is held by the author(s). Publication rights licensed to Aarhus University and ACM

5th Decennial Aarhus Conference on Critical Alternatives

August 17 -21, 2015, Aarhus Denmark

DOI: http://dx.doi.org/10.7146/aahcc.v1i1.21199 relation to the charisma of past technologies. This historical perspective highlights the ideological commonalities between all of these charismatic objects. It also suggests that far from being a new phenomenon, charismatic technologies have been captivating their users and admirers for decades, and will likely continue to do so for decades to come. We will see that charismatic technologies help establish and reinforce the ideological underpinnings of the status quo through utopian promises [39] - promises that persist even when the technology does not deliver.

The goal of this paper is to expose the ideological stakes that buttress charismatic technologies. Those who create, study, or work with technology ignore the origins of charisma at their own peril - at the risk of always being blinded by the next best thing, with little concept of the larger cultural context that technology operates within and little hope for long-term change. Recognizing and critically examining charisma can help us understand the effects it can have and then, if we choose, to counter them. However, it is also important to acknowledge that charisma can smooth away uncertainties and help us handle contradictions and obstacles. As such, the purpose of this paper is not to 'prove' charisma 'wrong,' because its rightness or wrongness is beside the point. As we will see, what matters is whether a technology's charisma is still alive.

This paper provides a framework for understanding how charisma operates in relation to technologies, how it might be identified, and what is at stake when we are drawn in. It provides tools for identifying charismatic technologies and teasing out the implications of this charisma, from the hardware and software of the object itself to the ensembles, agendas, and trajectories of the globalized organizations around it [18], and back down to the ways that those same groups shift, contest, or perpetuate the object's charisma. This borrows from Actor-Network Theory the idea that nonhuman "actors" have agency in technosocial discourses [33], and from Value-Sensitive Design a normative examination of the ways in which the myriad values influence design and use [19]. This analysis adds to these theories a detailed case study of the role that charismatic authority plays in the design and use of technologies, digging beneath professed values to identify the ideological underpinnings upon which values, and charisma, rest. 


\section{METHODS AND SOCIAL-HISTORICAL ORIENTATION}

This paper draws on archival research, interviews, and ethnographic observations conducted between 2008 and 2015. This includes an investigation of the forty-year development of the ideas behind One Laptop per Child (OLPC) through a review of the project's mailing lists, wikis, and discussion boards; the publication history of its founders; and interviews with some developers. The author also conducted seven months of fieldwork of an OLPC project in Latin America (see [5,6,53]), but this data is not directly included here. Analysis followed an iterative, inductive approach common in anthropology and cultural studies, combining the themes that emerge ground-up from a thorough understanding of participants' worldviews with a critical interpretation of these themes as 'texts' able to expand or contest broader theoretical questions [10].

This paper contextualizes the patterns noted in OLPC's rhetoric and design within the broader arc of technological development, as told by historians of technology. The combination of historical and contemporary data lends itself to reaching beyond the often bounded scope of qualitative research to answer more long-ranging questions about the trajectory of technological development and use.

\section{THEORIZING CHARISMATIC TECHNOLOGIES}

To explain the holding power that OLPC's laptop has had on technologists and others around the world, I develop the idea of a charismatic technology. This section defines charisma, outlines the salient features of charismatic technologies, and details the connection between charisma and related concepts from social theory including fetishism, religion, technological determinism, and ideology.

Charisma as a sociological construct was theorized by Max Weber to describe the exceptional, even magical, authority that religious leaders seem to have over followers. In contrast to (though sometimes subsumed by) other types of authority, such as traditional or legal/rational, charismatic authority is legitimized by followers through a belief that a leader has extraordinary, even divine, powers that are not available to ordinary people [68].

Though charisma is generally used to describe the power of humans, not objects, it has been applied to nonhumans as well. Maria Stavrinaki, for instance, describes the Bauhaus African Chair as a 'charismatic object' within the Bauhaus community [57]. Relatedly, Anna Tsing [59] discusses how the idea of globalization has been charismatic to some academics, who uncritically naturalize or even reinforce globalist agendas by characterizing globalization as universal and inevitable. Tsing's model of charisma - a destabilizing force that both elicits excitement and produces material effects in the world (even if these effects differ from those that were promised) - is at play here as well.

By treating an object as charismatic, these approaches, and this paper as well, utilize perspectives from actor-network theory (ANT), which subject both human and non-human 'actors' to the same analytical lens in a mutually-constituted network of relations [33]. ANT, however, tends to neglect the beliefs that underlie these networks, especially if these beliefs do not take material form [34:2]. Thus, while ANT provides tools for analyzing the 'scripts' that designers build into technologies [1], it falls short of providing the means to account for how ideological frameworks animate or inhabit these products - a gap charisma can fill.

Distinct from fetishism's focus on form, which stipulates a fixation on the materiality of the (presumably) passive object itself as a source of power, a charismatic object derives its power experientially and symbolically through the possibility or promise of action: what is important is not what the object is but what it promises to do. Thus, the material form of a charismatic technology is less important than how it invokes the imagination. As sociologist Donald McIntosh [36] explains, "charisma is not so much a quality as an experience. The charismatic object or person is experienced as possessed by and transmitting an uncanny and compelling force." A charismatic technology's promises are likewise uncannily compelling, evoking feelings of awe, transcendence, and connection to a greater purpose $[39,44]$.

Charisma moreover implies a persistence of this compelling force even when an object's actions do not match its promises - hence the magical element of charisma. This is where a charismatic technology's link to religious experience is especially strong, as a system built on faith that is maintained and strengthened outside of (or even counter to) the auspices of 'evidence' [2]. This is also one of the places that the consequences of charisma are most visible, as a technology's devotees maintain their devotion even in the face of contradictions.

This potential for charisma to override 'rational' thought is something that is not lost on marketers. While they may not call it as much, their promotions often tap into the charisma that certain technologies have, and journalists often echo it as well. In fact, religion scholar William Stahl examines the popular discourses about technology and concludes that "our language about technology is implicitly religious" [56:3]. Other scholars have also documented the connections between technology and religion, highlighting the prevalence of religious language in branding discourse [37,40,52,56], revealing parallels between religious and engineering practice [2], or showing how specific technologies are rhetorically connected to divinity and redemption in use $[11,28,31,39]$. Thus, while charismatic objects construct and reinforce their own charisma, media are often implicated in amplifying it, as we will see below.

In their often utopian promises of action, charismatic technologies are deceptive: they make both technological adoption and social change appear straightforward instead of a difficult process fraught with choices and politics. This gives charismatic technologies a determinist spirit, where technological progress appears natural, even inevitable. This naturalizing element can lead us to underestimate the sustained commitment needed for technological adoption. In 
building out the railroad in the mid-nineteenth century, for instance, Nye shows that the charisma of the locomotive led to the U.S. paying an enormous price in resources and lives in an attempt to realize the utopian promises of rail [44]. By the same token, charisma's naturalizing force can make critique and debate appear unnatural.

However, charisma contains an irony. A charismatic technology may promise to transform its users' sociotechnical existence for the better, but it is, at heart, fundamentally conservative. Just as charismatic leaders confirm and amplify their audiences' existing worldviews to cultivate their appeal [36], a charismatic technology's appeal is built on existing systems of meaning-making and largely confirms the value of existing stereotypes, institutions, and power relations. This unchallenging familiarity is what makes a charismatic technology alluring to its target audience: even as it promises certain benefits, it simultaneously confirms that the worldview of its audience is already 'right' and that, moreover, they are even savvier to have this technology bolster it.

This worldview that charisma reinforces is what social theorists refer to as an ideology: a framework of norms that shape thoughts and actions. Cultural theorist Stuart Hall describes an ideology as a "system for coding reality" that "becomes autonomous in relation to the consciousness or intention of its agents" [22:71]. We live with many ideologies, reinforced not just by charisma but across our socio-political landscape: neoliberal economics, patriarchal social structures, and Judeo-Christian ethics are among the many dominant ideologies in the United States, for instance.

Hall notes that 'ideology' has been useful in social theory as "a way of representing the order of things which endowed its limited perspectives with that natural or divine inevitability which makes them appear universal, natural and coterminous with 'reality' itself" [22:65]. What is important in this definition is the way that ideology fades into the background: by one metaphor commonly used in anthropology, ideologies are as invisible to most people as we imagine water is to a fish [15:123]. In Hall's words, an ideology "works" because it "represses any recognition of the contingency of the historical conditions on which all social relations depend. It represents them, instead, as outside of history: unchangeable, inevitable and natural" [22:76]. By referencing and reinforcing existing ideological norms, charismatic technologies by extension can also appear 'unchangeable, inevitable and natural.'

Thus, charismatic technologies help establish and reinforce the ideological underpinnings of the status quo. They do so through promises that may persist among true believers even when the technology does not deliver. The task of this paper, then, is to "break the spell of the present" [56], exposing the ideological stakes that underpin charisma. Technologists ignore the origins of charisma at their own peril - at the risk of always being blinded by the next best thing, with little concept of the larger cultural context that technology operates within and little hope for long-term change. Recognizing and critically examining charisma might, as Mosco explains, "help us to loosen the powerful grip of myths about the future on the present" [39:15].

Still, it is also important to recognize that charisma plays an important, even indispensable, role in our lives. Charisma whether from leaders or technologies - can provide direction and conviction, smoothing away uncertainties and helping us handle contradictions and adversities. Rob Kling asserts that faith in technology can play a major role in cultural cohesion: "During the 1930s," he explains, "this almost blind faith in the power of the machine to make the world a better place helped hold a badly shattered nation together" [30:48]. As such, the purpose of this paper is not to 'prove' charismatic technologies 'wrong,' because matters here is whether charisma is still ideologically resonant.

\section{THE CHARISMA OF ONE LAPTOP PER CHILD}

OLPC's laptop, called the 'XO,' was the first of its kind to combine a rugged design, an open-source educational software suite, and full (though purposefully underpowered, in an attempt to prolong battery life) computer functionality, with the goal of overhauling education across the Global South. The project is a culmination of over forty years of work at the MIT Media Lab and its predecessors, particularly the intellectual legacies of MIT professors Seymour Papert and Nicholas Negroponte. While many were involved in OLPC, Negroponte and Papert together were largely responsible for establishing the direction of the project.

Both Negroponte and Papert are themselves charismatic, and both used it to build the charisma of the OLPC project and the XO laptop. While Negroponte has been the public face of the project, glibly flinging XOs across stages at world summits to demonstrate their ruggedness [64] and talking about "helicopter deployments" of laptops to remote areas [66], Papert was the project's intellectual father. His whole career focused on the idea of computers for children, leading to the development of LOGO, Turtle Graphics, Lego Mindstorms, and, finally, One Laptop per Child. Though the results of these projects have been lackluster at best $[4,6,51,55,67]$, Papert is still often considered a central figure in education and design (e.g. $[8,20])$, and his books remain foundational to the curriculum at the MIT Media Lab [2].

While the charisma of these two men were important to OLPC, I also want to emphasize that OLPC's XO laptop itself included a host of charismatic features that were eagerly discussed in the tech community and media alike, even when some never actually existed and others did not work in practice. In this way, the machine itself embodied and performed its charisma, and the discussion around the machine amplified and perpetuated these promises.

One of the most charismatic features of the initial proposal for the laptop was a hand crank for manually charging it. Though this feature never existed in a working prototype and all laptops in use were charged via standard AC adapter [53], journalists still mention the hand crank or make claims based 


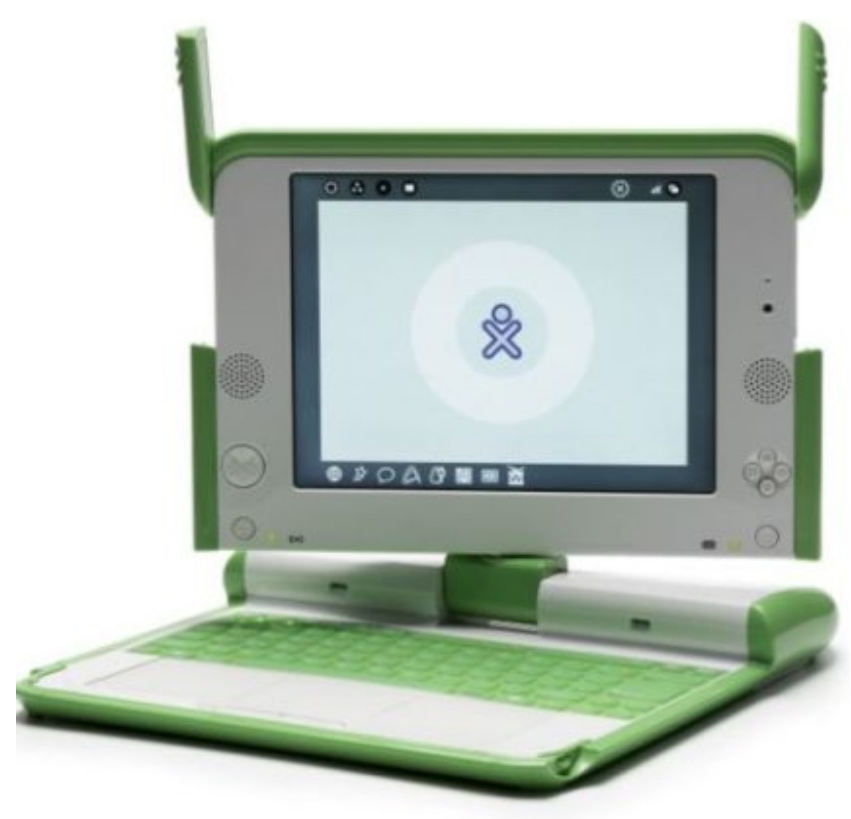

Figure 1. The XO in standard laptop configuration, showing the first-generation Sugar interface (promotional picture).

on its presumed existence. Two antennae "ears" on either side of the screen, which also acted as latches and covers for ports, were added to visually replace it (Figure 1). They also served to anthropomorphize the laptop, as did the person-like "XO" name/logo which, when turned on its side, was meant to look like a child with arms flung wide in excitement.

The XO included a "view source" keyboard button, a feature hailed as revolutionary even though web browsers had long included a similar function. Moreover, the button often did not work and I never saw it used in months of observations. The laptop's hardware was meant to be similarly accessible, and OLPC leaders boasted about the laptop being particularly easy to repair. However, compromises with manufacturers and cost-cutting made this promise unattainable as well, and projects were plagued with breakage $[4,53]$.

The laptop had an innovative screen, invented by fellow MIT Media Lab professor and founding OLPC contributor Mary Lou Jepsen, that could be swiveled and flattened, and its back light turned off, like an e-book - though I found that the screen was also the second-most-common component to break and the second-most-expensive to replace [53]. The first-generation $\mathrm{XO}$ included a mesh network so that laptops could connect to one another directly without an access point, though in practice the underpowered laptops would grind to a halt if more than a few were connected and the feature was dropped from later versions of the laptop's software $[53,65]$.

Even the original name of the project - the "hundred-dollar laptop" - was never achieved: the lowest price was $\$ 188$ $[6,53]$. This in part was because OLPC's goal of having hundreds of millions of laptops in use across the Global South also never came to fruition - instead, about 2.5 million have been sold, most of them in Latin America [6].
And yet, none of these niggling realities mattered. For several years after its debut and even today in the popular press, the project and its charismatic green machine were the darlings of the technology world. High-profile technology companies including Google, Sun, Red Hat, and others donated millions of dollars and hundreds of hours of developer labor to the project from 2005 to 2008. The open-source community, wooed by the promise of a generation of children raised on free software, continue to enthusiastically contribute to the development of OLPC's custom-built learning platform, Sugar. Unsubstantiated and quite likely apocryphal stories about children teaching parents to read, of impromptu laptopenabled classrooms under trees, or of the laptop's screen being the only light source in a village (never mind how the laptop itself was recharged) were echoed enthusiastically across the media and tech worlds. Even today, with ample evidence that OLPC has not lived up to these promises, they are still repeated, and $\mathrm{XO}$ laptops have been added to the collections of major art museums.

These hyperbolic claims themselves, whether based on design features or more general claims about how the laptop would change the world, became part of the machine's charisma. The project's leaders, like many who lead development projects, had the utopian, if colonialist $[6,17,27]$, desire to transform the world - not only for what they believed would be for the better but, as we will see, in their own image. Negroponte infamously said that the project and laptop "is probably the only hope. I don't want to place too much on OLPC, but if I really had to look at how to eliminate poverty, create peace, and work on the environment, I can't think of a better way to do it" [63]. Though Negroponte made an easy target by often saying outrageous things that sometimes left even others on the project shaking their heads or backpedaling, many on the project echoed variations on this particular theme.

This raises the question, though, of why these worlds so enthusiastically accepted these claims. Here is where the charismatic authority of the XO laptop becomes important. Again, my goal here is not to 'prove' OLPC's charisma 'wrong': highlighting the project's continued charm despite its many failures is simply a method for demonstrating that charisma is indeed at play. In the next three sections, I will show how this charisma was based on specific ideas about childhood, school, and computers. As I describe in more detail in [3], OLPC hoped to replace a school experience that Papert claimed had 'no intrinsic value' [49:24] with a computer to encourage children to learn to think mathematically [48]. This was aimed at elementary school students who were assumed to be precocious, scientificallyinclined, and oppositional. Not coincidentally, this target audience matched developers' conceptions of their own childhoods. In the following sections, I will briefly describe each of these and why they were important to the charisma of OLPC's XO laptop. Then I will show that these same themes undergird a number of other historically charismatic technologies, demonstrating charisma's conservatism. 


\section{The charisma of childhood}

One Laptop per Child explicitly stated and implicitly built into their laptop the idea that children are born curious and only need a small impetus (such as a computer or an electronics kit) to keep that curiosity alive and growing. OLPC moreover specified the kinds of learning that children are naturally inclined to do: engineering-oriented tinkering. In this section, we will briefly consider the cultural narratives that Papert, Negroponte, and others draw on about what childhood should mean and what constitutes a good one, narratives that have become deeply rooted in middle-class American culture and reflect American cultural values such as individualism and (certain kinds of) creativity.

This ideology of childhood, though seemingly universal, is historically, geographically, and socioeconomically situated. Childhood came to be understood as a distinct developmental state in nineteenth-century Europe and America $[12,26,38,70,71]$, an ideological shift that was justified with Romantic-era ideals of childhood as a noble state closer to nature. These ideologies of childhood spread to mainstream middle-class parenting culture by the mid-twentieth century $[26,32,70]$, when the idea of nurturing childhood creativity, play, and individualism through consumerism (via large numbers of aspirational toys) gained popularity among middle-class white American families [45,46].

Around this time, toy manufacturers began to reinforce the idea that engineering was a space for natural masculine creativity through construction toys aimed at boys $[16,45,46]$, even though those patterns of play were relatively new and far from universal [12]. Alongside these shifts, 'healthy rebellion' also became an accepted part of American boy culture $[38,46]$. Far from the more ideologically intimidating rebellion that threatens to actually change the status quo, the rebellion that is sanctioned in boyhood is often tolerated as 'boys will be boys' or even encouraged as free-thinking individualism. From Mark Twain's Tom Sawyer to today, popular culture has linked these relatively harmless forms of rebellion against school and society with creative confidence, driven by 'naturally' oppositional masculine sensibilities.

The charisma of OLPC's laptop references this ideology of childhood. As I show in [3], though the XO was ostensibly for children of any gender, its design echoed tropes of boyhood specifically: its mesh network embodied a resistance to authority and its programming-focused applications echoed the engineering toys that companies had been marketing to boys for almost a century before [46]. Papert's and Negroponte's writing also often praised iconoclastic or free-thinking children - generally boys - who took to computers (and to their experiments) easily. In the process, they glossed over the many complexities of childhood - not to mention how things like household instability or food insecurity affect learning - by universalizing children as natural 'yearners' [49].

These actors also referenced these ideologies of childhood in discussing themselves. In his writing, for example, Papert describes himself and others like him as part of a rarefied group that has managed to hold onto the magic of childhood: independent thinkers, lifelong learners, and, not coincidentally, many in the hacker community. They generalized from experiences with largely white, middleclass American youth - or from their own idiosyncratic childhoods - that all, most, or at least the most 'intellectually interesting' [49:44-50] children are innately drawn to tinkering with computers and electronics, or in Papert's words, 'thinking like a machine' [48].

\section{The anti-charisma of school}

The One Laptop Per Child project frames itself and its laptop as a radical break from an unchanging global educational tradition $[7,43,48-50]$. In contrast to the naturally curious state of children, OLPC leaders paint school as a stultifying rote experience that has not changed in over a century $[42,43,48,49]$. In his writing, Papert villanizes what he calls 'instructionism,' or lecture-heavy, curriculum-based education. Papert argues that instructionism creates people 'schooled' to think in limited ways and seek validation from others out of 'yearners,' the innate, creative, playful state of children, focused on thinking independently, not caring what others think, and seeking answers via many routes for questions in which they are personally interested [49:1].

Papert is unequivocal about his disdain for school, calling the classroom 'an artificial and inefficient learning environment' [48:8-9] with 'no intrinsic value,' its purpose molding children out of their natural state and into a more socially 'desirable' form [49:24]. With the exception of a few brave teachers who fight against the establishment [49:3], Papert's description of a monolithic 'School' (always capitalized) is of an institution unchanged for over a century, 'out of touch with contemporary life,' and shamelessly 'impos[ing] a single way of knowing on everyone' [49:1-6].

Papert is not alone in the expressing scorn for education. Many of OLPC's contributors, whether affiliated with MIT (including MIT professors) or the open-source software community, describe similar sentiments (e.g. [9,25,41]). Even though not all people in the OLPC community actually rejected school (and many, in fact, excelled), they published and shared narratives about how boring, stifling, and unfulfilling classroom education was.

These narratives resonated in the technology community as well as across American culture more broadly, where it is common, and even encouraged, to disparage public education and recount tales of terrible teachers (while excellent ones are often forgotten, and the role of school as a social leveler or cultural enricher are similarly unmentioned). In this way, the anti-charisma of school has become a common cultural trope, and we will critically examine it later in this paper. For OLPC, it served two purposes. First, it aligned the project with this broader backlash against public school. Second, it provided a rhetorical foil to ideologies of childhood - an opportunity to reinforce the importance of individualism, (technically-inclined) play, and rebellion important to the idea of childhood OLPC relies on. 


\section{The charisma of computers}

As an alternative to school, Papert proposes giving each child a 'Knowledge Machine,' a clear forerunner to OLPC's XO laptop. Indeed, many who have watched a child with a touchscreen or a videogame have marveled at how children seem to be naturally enamored with technology. Stories abound of precocious young children, especially boys, who seem to take to electronics fearlessly and naturally $[41,48,49]$. Both Papert and Negroponte rhapsodize about the 'holding power' that computers can have. Papert says,

The computer is the Proteus of machines. Its essence is its universality, its power to simulate. Because it can take on a thousand forms and can serve a thousand functions, it can appeal to a thousand tastes. [48:viii]

The stories OLPC tells about the potentials of its charismatic laptop roll into one package many of the promises connected to computers and cyberspace: of newfound freedoms and potentials for computer-based self-governance, of the inversion of traditional social institutions (putting, of course, the computer-savvy like themselves at the top), of the "flattening" of bureaucracies, of the end of geographic inequity, of a "reboot" of history $[30,39,44,54,60,61,69]$. Even though computerization has largely entrenched existing power structures, these ideals of the computer age live on, especially among technologists whose cocooned middle-class existence may not bring them in contact with those whose lives and livelihoods have not benefited from these technologies or who have been actively excluded from the wealth in the technology world.

The connection between rebellion and computing cultures is also well-established, particularly as countercultural norms of the 1960 s were embraced by early cyberculture communities [60,61]. Narratives about the kinds of 'all in good fun' rebellion that computers could enable were popularized with the establishment of the 'hacker' identity in the 1980s (e.g. $[21,35])$. This imbued cyberspace with metaphors of the Wild West, of Manifest Destiny, of a new frontier of radical individualism and ecstatic self-fulfillment [60,61,69]. It also encouraged a libertarian sensibility, where each actor is considered responsible for their own actions, education, and livelihoods - conveniently ignoring the massive infrastructures that make the cyberspace 'frontier' possible.

These ideals of computers and cyberspace motivated OLPC's commitment to provide computers to children around the world, and helped the project resonate with many, from journalists to governments, similarly enamored with technology. Imbued with this infinite potential, laptops could take priority over teachers, healthcare, even food and water. And they took on yet greater power in utilizing ideas of childhood, school, and computers together, as we see next.

The nexus of childhood, computers, and learning: the charisma of the self-taught hacker

These three ideologies come together in One Laptop per Child through the narrative of the self-taught hacker and developers' desire to bring the experiences of their own childhoods to other children around the world [3]. Papert, for one, explicitly credits his own formative experiences with computers as inspiration for the project. "I realized that children might be able to enjoy the same advantages" with computers as himself and other MIT hackers, Papert explains in his book The Children's Machine - "a thought that changed my life" [49:13].

In conversations with OLPC developers and those who identify as 'hackers' across Silicon Valley and in Boston, I often encountered the story of 'teaching myself to program.' These actors describe learning about computers as something they did on their own, driven by feelings of passion and freedom, and independent of any formal instruction $[24,25,41,58]$ - just as OLPC's intended beneficiaries are meant to do. Shunning school in favor of this libertarian learning model, these people saw their excitement kindled and powers developed from their personal relationship with computers, with hours spent tinkering with Commodore $64 \mathrm{~s}$ or Apple IIs, chatting with others in BBS's or Usenet groups.

But as I dug deeper into how this self-learning worked, I found that in all cases they benefited from many oftenunacknowledged resources. This included a stable home environment that supported creative (even rebellious) play, middle-class resources and cultural expectations, and often (though not always) a father who was a computer programmer or engineer. Moreover, many also acknowledged, sometimes readily, that they were not typical among their peers in their youth, and were often shunned for their unusual interests or obsessions. Even among peers who also had computers at home they were often unique in their interest in learning to 'think like a machine,' while many others with the same of access were not nearly as captivated by computers.

However, neither Negroponte nor Papert discuss the possibility that they, and their students at MIT, enjoyed privileged and idiosyncratic childhoods, nor do they dwell on the sociotechnical infrastructure that enabled that privilege. If anything, Papert's accounts of employing his theories in classrooms or other settings (e.g. see $[48,49]$ ) reinforce notions of exceptionalism by focusing exclusively on the few engaged children, those rare emblems of 'success' who appear to prove his theories, and ignoring the rest.

OLPC's idea of the self-taught learner who disdains school for computers also discounts the critical role that various institutions - peers, families, schools, communities, and more - play in shaping a child's educational motivation and technological practices. Instead, Papert and other OLPC developers essentialize the child-learner and make the child and the laptop the primary agents in this technosocial assemblage, favoring technological determinism - all it takes is the right kind of computer to keep kids as 'yearners' - over the complicated social processes involved in constructing and negotiating childhood.

This reliance on personal experience underscores an ideological slippage between the ideas taken up by XO 
laptop designers and children's activities on the ground $[5,6]$. OLPC aimed to provide access to pedagogical materials with the assumption that children's interests would take care of the rest, but did not account for their own idiosyncratic childhoods and ultimately reinforced existing socioeconomic and gender inequalities $[5,6,53]$. Their reliance on personal experience also enabled their naturalized images of childhood to justify a particular set of normative social objectives. Locating these slippages, and the tenacity to which supporters held to their ideals even when confronted with them [2], provides a powerful method of identifying charisma and uncovering its possible consequences.

\section{PUTTING OLPC'S CHARISMA IN HISTORICAL CONTEXT}

As we have seen, OLPC's charisma has the ability to evoke awe, a feeling of spiritual transcendence, and utopian visions for the kind of world that its laptops might make possible. In particular, the XO rolled into one package many of the promises also connected to computers and cyberspace, to childhood and play, and to learning outside of school. A key component of this charisma was its ability to evoke the nostalgic stories that many in the technology world tell about their own childhood experiences with computers. The project has the utopian, if colonialist [17,27], desire to remake the world in its own image.

However, OLPC's XO laptop is but the latest in a long line of charismatic technologies. Historians of technology show that from the railroad in the mid-nineteenth century to the Internet today, many new technologies have been hailed as groundbreaking, history-shattering, and life-redefining. "Since the earliest days of the Industrial Revolution," Langdon Winner writes, "people have looked to the latest, most impressive technology to bring individual and collective redemption. The specific kinds of hardware linked to these fantasies have changed over the years ... [b]ut the basic conceit is always the same: new technology will bring universal wealth, enhanced freedom, revitalized politics, satisfying community, and personal fulfillment" [69:12-13]. Here, I briefly describe the history of charismatic technologies as a way to locate and bound OLPC's charisma.

Historian David Nye identifies the first time feelings of redemption were linked to a new technology in his description of the locomotive of the mid-nineteenth century. From the inauguration of America's first rails in Baltimore in 1828 to the completion of the transcontinental line at Utah's Promontory Point in 1869, Nye describes a nation gripped with railroad mania. The railroad was implicated in dozens of hyperbolic claims, including the "annihilation of space and time" [29] with its sustained speed, the demise of manual labor with steam, a liberation of humankind from provincialism via increased contact and communication, the triumph of reason and human ingenuity, an 'engine' of progress and Western expansion, and a guarantor of economic development for all it reached [44]. ${ }^{1}$

Even when railroads cost vastly more time, money, and human lives to construct than anticipated, and even when they did not bring endless prosperity and worldliness to their termini, the locomotive's charisma persisted for some time, in the same way that subsequent charismas did over a century later as highways were laid down alongside or over rail lines and as airports replaced train stations as the newest symbols of progress and modernity [39,44,54]. Indeed, these same utopian discourses were applied to many other technological advances over the next century - many of which we now take for granted - including the steamboat, canals, bridges, dams, skyscrapers, the telegraph, electricity, the telephone, the radio, the automobile, television, cable television, and more $[16,39,44,54,62]$. Even the airplane was hailed as a "winged gospel" that would "foster democracy, equality, and freedom" - despite its terrifying wartime role [69].

While it may be easy to discount these past charismatic technologies given the perspective and tarnish of time, they contain two lessons, one about the enduring importance of charisma to the modern cultural imagination, and the other about its limits. In particular, there is a striking parallel between the charisma of computers that OLPC draws on and these earlier charismatic technologies. Historian Howard Segal notes that the rhetoric of the power of the Internet to spread democracy "was identical to what thousands of Americans and Europeans had said since the nation's founding about transportation and communications systems, from canals to railroads to clipper ships to steamboats, and from telegraphs to telephones to radios" [54:170]. Vincent Mosco also notes these similarities in a call for both more empathy for the past and more skepticism of the present. "We look with amusement, and with some condescension," he writes, "at nineteenth-century predictions that the railroad would bring peace to Europe, that steam power would eliminate the need for manual labor, and that electricity would bounce messages off the clouds, but there certainly have been more recent variations on this theme" [39:22].

In short, a historical perspective helps (in William Stahl's words) "break the spell of the present" [56]. It demonstrates that today's charismatic technologies are neither natural nor inevitable, but are ideologically conservative: even as they promise revolution, they repeat the charisma of past technologies and ultimately reinforce the status quo. This, in turn, allows us to better identify new charismatic technologies and to understand charisma's consequences. The next section examines a charismatic technology that provides these lessons for One Laptop per Child: the radio.

\footnotetext{
${ }^{1}$ Nye also notes the flip side of the sublime: a small group decried the locomotive as a "device of Satan" because of its 'unholy' speeds [44]. While a discussion of dystopianism is beyond the scope of this paper, it is the flip side of utopianism: though ruled by fear instead of hope, it is still beholden to the same ideologies $[30,39,69]$.
} 


\section{Lessons from the charismatic radio}

Of all the charismatic technologies of the past, the one that has the strongest resonances with the charisma of computers, education, and childhood - charismas that OLPC relies on is the radio. Aside from an increasingly marginalized culture of HAM radio operators, it can be hard to imagine radio in the U.S. (today so often a commercialized audio wasteland of top-40 songs on repeat, with a few public stations limping from one pledge drive to the next) as an intensely charismatic technology. But radio took 1920's America by storm, capturing the country's collective imagination with promises blending technological miracles and manifest destiny. Historian Susan Douglas explains that radio, as envisioned in 1924, "was going to provide culture and education to the masses, eliminate politicians' ability to incite passions in a mob, bring people closer to government proceedings, and produce a national culture that would transcend regional and local jealousies" [16:20]. Commentators described the replacement of telegraph wires with radio waves with psychic metaphors and compared it to magic [16:41].

Many of the amateur enthusiasts and educators who pioneered radio were especially excited by the medium's apparent ability to transcend political and economic controls, enabling virtual communities and informed populism - all hopes that have been echoed more recently about computers, the Internet, and OLPC. After all, Mosco observes wryly, "How could any material force get in the way of invisible messages traveling through the ether?" [39:27]

However, many things can and did get in the way of radio's utopian dreams. Douglas notes that until the Internet, the radio was the main medium where struggles between commercialism and anti-commercialism played out, in a cyclic pattern, over decades [16:16]. When nascent radio stations and other businesses realized how much money could be made selling advertising time on the radio, they advocated for commerce in the 'ether.' Governments, too, wanted to control this new technology, and most either took complete control or shared bandwidth with industry, sidelining educators, amateur operators, and other early enthusiasts with little leverage to realize their own hopes. Even by the 1930s, a mere decade after radio's most charismatic days, "radio was no longer the stuff of democratic visions" [39:27] - much like OLPC has receded into the fog of history for many former supporters a decade after its debut, or the Internet, now decades old, is gradually co-opted for commercial interests.

Still, the small group of dedicated enthusiasts who had pioneered the medium - almost all men - continued to use radio to "rebel against the technological and programming status quo in the industry" [16:15], flaunting intellectual property, government rules, and big business in the process [39:2]. This group continued to conceptualize their pastime of tinkering, listening, and programming the radio as a "subversive" activity [16:15] and maintained their equally subversive hopes for the future of the wireless medium. And it is understandable that they would be loath to give up their dreams. These "Radio Boys," as Mosco identifies them, were initially the "heroes" of the Radio Age, "youngsters who lent romance and spirit to the time by building radios, setting up transmitters, and creating networks" [39:2]. But as compelling as their messages may be to anyone sympathetic to contemporary hacker culture, the dreams of the Radio Boys did not prevail. As radio became more commercialized, the connection between technological tinkering and utopian thinking largely receded into niche communities such as HAM radio [23] until reappearing, with a new set of actors but some remarkably similar practices, around the networked personal computer $[35,58,61]$ - the actors that Papert says inspired his work on designing a 'children's machine.'

Historians have argued that remarkable parallels between this group and the 'hackers' who designed personal computers, the Internet, and OLPC's XO laptop are no accident. The charisma of radio, computers, the Internet, locomotives, and more draws on the same set of utopian stories about technology, youth, masculinity, rebellion, and selfdetermination. For instance, the individualist strains in these earlier technologies found voice in the cyber-libertarianism of recent decades [61]. The new frontiers of the imagination that the railroad opened in mid-nineteenth century America are rhetorically echoed in the new frontiers of radio in the 1920 s and cyberspace in the 1980s, spaces of radical individualism and ecstatic self-fulfillment [60,61,69]. The charismatic appeal of tinkering that 1920s 'Radio Boys' championed found voice again in computer hacking, in projects like OLPC, and most recently in maker culture [3]. Thus, while the technologies that these charismas are attached to may shift with time, the charisma lives on.

What could be problematic about the feelings that these charismatic technologies can evoke, at least when still relatively new? After all, many of these technologies did, in time, transform the technosocial worlds in which they existed. However, Vincent Mosco argues that we actually prevent these technologies from having their full effect as long as we remain enthralled by their charisma. It was not until they recede into the 'mundane' and we understand how they could fit into the messy realities of daily life, rather than making us somehow transcend it, that they have the potential to become a strong social force $[39: 2,6,19]$. If this is the case, then perhaps it is just now, with the spell of OLPC broken, that the XO laptop can start to show its lasting effects among those using it. Time, and independent analysis [6], will tell.

\section{Lessons from technologies in educational reform}

Education is of course not immune to the draw of charismatic technologies. In fact, educational reform has been a target of techno-utopian discourse long before the One Laptop per Child project was announced, even before Papert began his career of studying children and computers. Charismatic technologies from radio to the Internet have been hailed as saviors for an educational system seemingly perpetually on the brink of failure [62]. The hyperbolic promises of OLPC echo these ongoing efforts to combine the twin promises of charismatic technology and school reform to reach for utopia. 
Because learning was the central goal of OLPC, examining the history of charisma in this context lets us contextualize the project and identify other charismatic technologies that pervade education. Moreover, a survey of the history of school reform shows that much of the anti-charisma of school described above is based more in stereotypes than fact, reinforced by a century of technological failures in education. Finally, we will see that education reforms like OLPC are often compelled to use charismatic technologies to promise utopia in order to secure attention and funding, which then sets them up for failure and short-lived projects. As reformers then shift to the next charismatic technology, charisma will continue to impede real, if incremental, change.

Over at least the last century and a half, American schools have been simultaneously held up as the foundation for reforming society and under constant pressure to reform themselves. Starting in the 1830s, upper-class activists such as Horace Mann evangelized the idea of 'common schools' as a savior from moral ruin, detailing the horrors that could result (and, in some cases, were resulting, for instance via unregulated child labor) if the country did not adopt universal public schooling $[14: 8,62: 1,16,141-142]$. Far from the 'factory worker mills' framed in some more recent educational reform literature (see $[48,49]$ for examples from Papert), public schools and subsequent innovations in schooling such as age-organized instruction (and sometimes the abandonment of it), curriculum-based instruction (and sometimes the abandonment of it), cheap paper and textbooks, kindergarten, subject-separated instruction, middle school, school lunch, desegregation, televised instruction, and even standardized tests were all framed by socially and politically elite reformers for more than a century and a half as a cure-all for assimilating immigrants and marginal populations, ending child labor, modeling good citizenship, and instilling morality in the next generation $[13,14,62]$.

The panacean promise of education was gradually shifted in the late twentieth century from moral to economic. In introducing "Great Society" educational reforms meant to eliminate poverty in the 1960s, President Johnson avowed that "the answer to all our national problems comes down to a single word: education" [62:2]. Two decades later, as perceptions of the United States' waning influence prompted a sense of panic about reforming education to achieve economic competitiveness, President Reagan's National Commission on Educational Excellence and Reform took up the specter of impending dystopia in an alarmist report titled A Nation at Risk: The Imperative For Educational Reform that to this day motivates U.S. educational reform $[13,14,62]$.

Throughout these efforts, reformers often implicated the technologies most charismatic at the time as integral to achieving their visions. Some technological innovations, like chalkboards, inexpensive paper, overhead projectors, and computer-assisted standardized testing, have, in fact, had large and lasting effects on schools. But some of the most charismatic technologies have not. Many media and communication technologies including early motion pictures, radio, television, and computers were (and, in the latter case, still are) often championed as fast cure-alls for educational woes by innovators who were often not involved in public schools themselves. "Impatient with the glacial pace of incremental reform, free of institutional memories of past shooting star reforms" that left no effect in day-to-day schooling, and "sometimes hoping for quick profits as well as a quick fix," Tyack and Cuban explain, these reformers "promised to reinvent education" with technology [62:111].

Like the more general utopian visionaries of technology discussed in previous sections, many of these innovators over-promised the scope and ease of change and lacked a nuanced understanding of the day-to-day social, cultural, and institutional roles of the actors most directly involved in the worlds they wanted to transform. When the messy, expensive, time-consuming realities of using technology in the classroom inevitably clashed with hyperbolic promises, disillusioned innovators, along with the media and the general public, would often blame schools and especially teachers for not solving problems with technological adoption that were, in reality, beyond their reach. Then, research on the effects on the new technology in the classroom would start to roll in, showing that the technology was, as Tyack and Cuban describe, "generally no more effective than traditional instruction and sometimes less" [62:121-122]. Meanwhile, attention and resources had been diverted from more complicated, expensive, or politically charged social or educational reforms that did not promise a quick fix [62:3] and were thus less 'charismatic.'

This is not to say that reform or technological adoption in education is impossible. Though the broader institutional structures of schools and many of the strategies teachers use to reach students appear to be unchanged, there have been many successful innovations that have altered the daily lives of students and teachers, sometimes dramatically. Still, even more realistic reforms well-grounded in the realities of students and schools sometimes have difficulty gaining broad popular support outside of the school unless they add a charismatic gloss of rapid, revolutionary change.

This charismatic pressure can put even open-eyed educational reformers in a catch-22 [6]. They must promise dramatic results to gain the social and financial support for reforms, and then they must either admit to not achieving their goals, or pretend that they did achieve them. Either way, funders will declare that the project is finished and withdraw financial support, and then researchers and other observers will begin to note the discrepancies between reformers' promises and their own observations. Thus, projects that rely on charismatic technologies are often short-lived, cut off before charisma recedes into the background and the technology can become part of everyday classroom experience. This catch-22 has dogged educational reform for well over a century, and as the educational technology community moves on to the next charismatic technologies 
(whether they be MOOCs or makerspaces), it will continue to hamper the possibility of real, if incremental, change.

What is the alternative to this catch-22 of charismatic education reform? Incremental reforms, what Tyack and Cuban call "tinkering," are more effective in the long-term, even if they are not charismatic. "It may be fashionable to decry such change as piecemeal and inadequate, but over long periods of time such revision of practice, adapted to local contexts, can substantially improve schools," they explain. "Tinkering is one way of preserving what is valuable and reworking what is not" [62:5].

\section{CONCLUSION}

Through an analysis of One Laptop per Child and a survey of past charismatic technologies, this paper exposes the ideological stakes that underpin charisma - the ability for technologies (or, as originally theorized, people [68]) to evoke feelings of awe, transcendence, and connection to a greater purpose. It shows how the promises that charismatic technologies make are ideologically charged, how they can be identified, and what is at stake when we are drawn in. While it may be easy to discount examples from the past given the perspective and tarnish of time, taking a historical perspective on charismatic technologies show us how conservative charisma actually is - the same kinds of promises have been made over and over, with different technologies - and also how unattainable its promises are.

Examining charisma can help us understand its effects and, through understanding, counter them. This analysis is meant to help 'make the familiar strange,' in Stuart Hall's words [22], helping researchers in human-computer interaction to identify the ideological commitments of the technology world. Analyzing a technology's charisma helps us recognize ideologies that may otherwise be as invisible as water is to the proverbial fish. While concrete design suggestions are not the goal of this paper, this analysis may also help designers who often hope to 'do good' through technological intervention in ways similar to those analyzed here - identify their own ideological commitments.

To OLPC's contributors, we saw that the charisma of the XO laptop affirmed their belief in the power of computers in childhood, imposed coherence and direction on their work, and gave them reasons to push back against doubters, even in the face of what might otherwise feel like overwhelming odds or ample counterevidence [2]. On the other hand, we saw that charisma could also have a blinding effect. It prevented those on the project from recognizing or appreciating ideological diversity, much less constructively confronting problems of socio-economic disparity, racial and gender bias, or other issues of social justice beyond most of their personal experiences [47]. OLPC's XO laptop was charismatic to them because it mirrored their existing ideologies and promoted a social order with them at the top.

As a result, their narratives not only glorified childhood, they specified the kinds of learning that children are naturally inclined to do. In glossing over the many complexities of childhood with universalizing concepts like 'yearners' and 'schoolers,' Papert and others in OLPC drew on cultural narratives about what childhood should mean and what constitutes a good one, narratives that have become deeply rooted in American culture and reflect American cultural values such as individualism and (certain kinds of) creativity. These actors have generalized from their experiences with largely white, middle-class American youth - or from their own idiosyncratic childhoods - that all, most, or at least the most 'intellectually interesting' [49:44-50] children are innately drawn to tinkering with computers and electronics, or in Papert's words, 'thinking like a machine' [48].

The case of OLPC shows us why it is dangerous to ignore the origins of charisma: one risks being perpetually blinded by the newest charismatic technology as a result. Indeed, those who pin reform efforts on charismatic technologies are often caught in a catch-22 where their projects are cut short whether they register success or not, because the promises of charisma are ultimately unattainable.

Moreover, as long as we are enthralled by charisma we might actually prevent these technologies from becoming part of the messy reality of our lives, rather than helping us transcend it. We must remember that charisma is ultimately a conservative social force. Even when charismatic technologies promise to quickly and painlessly transform our lives for the better, they appeal precisely because they echo existing stereotypes, confirm the value of existing power relations, and reinforce existing ideologies. Meanwhile, they may divert attention and resources from more complicated, expensive, or politically charged reforms that do not promise a quick fix and are thus less 'charismatic.'

Still, it is also important to recognize that charisma plays an important role in smoothing away uncertainties, contradictions, and adversities. As such, the purpose of this paper is not to 'prove' charisma 'wrong.' What matters is whether a technology's charisma is ideologically resonant whether it taps into deep-seated cultural values and identities, as OLPC does with childhood, school, play, and technology.

This paper's intention is likewise not to advocate for an eradication of ideologies; just as it is impossible to escape the bounds of our own subjective points of view, so too is it impossible to operate entirely outside of the frameworks of ideologies. However, a large body of Marxist theory (e.g. see [22]) notes that becoming cognizant of the ideological frameworks in which we operate allow us to evaluate whether they are really serving the purposes we hope or assume they are. Only by way of this cognizance can we shift them if they are not.

\section{ACKNOWLEDGMENTS}

I am indebted to many friends and mentors for helping me develop the ideas presented in this paper. In particular, Fred Turner and Eden Medina pushed me to articulate the importance of charismatic technologies, and Paul Dourish, Lilly Irani, Daniela Rosner, Ingrid Erickson, and Marisa Brandt helped me flesh out the salient features of charisma. I 
also thank all of the participants involved in my research on One Laptop per Child.

\section{REFERENCES}

1. Madeleine Akrich. 1992. The De-Scription of Technical Objects. In Shaping Technology, Wiebe E Bijker and John Law (eds.). MIT Press.

2. Morgan G. Ames, Daniela K. Rosner, and Ingrid Erickson. 2015. Worship, Faith, and Evangelism: Religion as an Ideological Lens for Engineering Worlds. Proc. CSCW 2015, ACM Press.

3. Morgan G. Ames and Daniela K. Rosner. 2014. From drills to laptops: designing modern childhood imaginaries. Information, Communication \& Society 17, $3,357-370$.

4. Morgan G. Ames, Mark Warschauer, and Shelia R. Cotten. 2016. The "Costly Lesson" of One Laptop per Child Birmingham. In When School Policies Backfire, and What We Can Learn, Michael A. Gottfried and Gilberto Q. Conchas (eds.). Harvard Education Press.

5. Morgan G. Ames. Learning Consumption: Media, Literacy, and the Legacy of One Laptop per Child. The Information Society, in press.

6. Morgan G. Ames. 2014. Translating Magic: The Charisma of OLPC's XO Laptop in Paraguay. In Beyond Imported Magic: Essays in Science, Technology, and Society in Latin America, Eden Medina, Ivan da Costa Marques, Christina Holmes (eds.). MIT Press, 369-407.

7. Walter Bender. 2007. OLPC: Revolutionizing How the World's Children Engage in Learning.

8. Paulo Blikstein. 2013. Seymour Papert Tribute at IDC 2013 Panel Avant-propos: Thinking about Learning, and Learning about Thinking.

9. Chris Blizzard at OLPC Analyst Meeting. 2007.

10. Michael Burawoy. 1998. The Extended Case Method. Sociological Theory 16, 1, 4-33.

11. Heidi A. Campbell and Antonio C. La Pastina. 2010. How the iPhone Became Divine: New media, religion and the intertextual circulation of meaning. New Media \& Society 12, 7, 1191-1207.

12. Howard P. Chudacoff. 2007. Children at play: An American history. NYU Press.

13. Larry Cuban. 1986. Introduction. In Teachers and Machines: The Classroom Use of Technology Since 1920. Teachers College Press.

14. Larry Cuban. 2001. Oversold and underused: Computers in the classroom. Harvard Univ. Press.

15. Sidney I. Dobrin. 1997. Constructing Knowledges: The Politics of Theory-Building and Pedagogy in Composition. SUNY Press.

16. Susan Douglas. 2004. Listening In: Radio and the American Imagination. U. Minnesota Press.
17. Paul Dourish and Scott D. Mainwaring. 2012. Ubicomp's colonial impulse. Proc. UbiComp '12, ACM Press.

18. James Ferguson. 2006. Global Shadows: Africa in the Neoliberal World Order. Duke Univ. Press.

19. Batya Friedman, Peter H. Kahn, and Alan Borning. 2006. Value-Sensitive Design and Information Systems. In Human-Computer Interaction in Management Information Systems: Foundations, P. Zhang and D. Galletta (eds.). M.E. Sharpe, Inc.

20.Gerald Futschek and Chronis Kynigos (chairs). 2014. Constructionism and Creativity conference.

21. William Gibson. 1984. Neuromancer. Ace Books.

22. Stuart Hall. 1982. The Rediscovery of "Ideology": The Return of the Repressed in Media Studies. In Culture, Society, and the Media, Michael Gurevitch, Tony Bennett, James Curran, Janet Woollacott (eds.). Methuen, 56-90.

23. Kristen Haring. 2007. Ham Radio's Technical Culture. MIT Press.

24. Carlene Hempel. 1999. The miseducation of young nerds. http://jimhoeg.com/jimmy/proflife/miseducation.htm

25. Benjamin Mako Hill. 2002. The Geek Shall Inherit the Earth: My Story of Unlearning. http://mako.cc/writing/ unlearningstory/StoryOfUnlearing.html

26. Diane M Hoffman. 2003. Childhood Ideology in the United States: A comparative cultural view. International Review of Education 49, 1-2, 191-211.

27. Lilly Irani, Janet Vertesi, Paul Dourish, Kavita Philip, and Rebecca E. Grinter. 2010. Postcolonial Computing: A Lens on Design and Development. Proc. CHI 2010, ACM Press, 1311-1320.

28. Kevin Kelly. 1999. Nerd theology. Technology in Society 21, 4, 387-392.

29. Scott Kirsch. 1995. The incredible shrinking world? Technology and the production of space. Environment and Planning D: Society and Space 13, 5, 529-555.

30.Rob Kling. 1996. Computerization and Controversy: Value conflicts and social choices. Morgan Kaufmann.

31.Pui-Yan Lam. 2001. May the Force of the Operating System be with You: Macintosh Devotion as Implicit Religion. Sociology of Religion 62, 2, 243-262.

32. Annette Lareau. 2003. Unequal Childhoods: Class, Race, and Family Life. U. California Press.

33. Bruno Latour. 2005. Reassembling the Social: An introduction to actor-network theory. Oxford Univ. Press.

34.John Law. 1992. Notes on the Theory of the Actor Network: Ordering, Strategy and Heterogeneity. Systems Practice 5, 4, 379-393.

35. Steven Levy. 1984. Hackers: Heroes of the Computer Revolution. Anchor Press Doubleday. 
36. Donald McIntosh. 1970. Weber and Freud. American Sociological Review 35, 5, 901-911.

37. Scott Forsyth Mickey. 2013. Constructing The Prophet: Steve Jobs and the Messianic Myth of Apple.

38. Steven Mintz. 2004. Huck's Raft: A History of American Childhood. Harvard Univ. Press.

39. Vincent Mosco. 2005. The Digital Sublime: Myth, Power, and Cyberspace. MIT Press.

40. Albert M. Muniz Jr. and Hope Jensen Schau. 2005. Religiosity in the Abandoned Apple Newton. Journal of Consumer Research 31, 737-747.

41. Nicholas Negroponte. 1996. Being Digital. Vintage Books.

42. Nicholas Negroponte. 1998. One-Room Rural Schools. WIRED Magazine.

43. Nicholas Negroponte. 2006. No Lap Un-Topped: The Bottom Up Revolution that could Redefine Global IT Culture.

44. David Nye. 1996. American Technological Sublime. MIT Press.

45. Amy F. Ogata. 2013. Designing the Creative Child: Playthings and Places in Midcentury America. U. Minnesota Press.

46. Ruth Oldenziel. 2008. Boys and Their Toys: The Fisher Body Craftsman's Guild, 1930-1968, and the Making of a Male Technical Domain. Technology and Culture 38, 1, 60-96.

47. Nelly Oudshoorn, Els Rommes, and Marcelle Stienstra. 2004. Configuring the User as Everybody: Gender and Design Cultures in Information and Communication Technologies. Science, Technology \& Human Values 29, 1, 30-63.

48. Seymour Papert. 1980. Mindstorms: Children, Computers, and Powerful Ideas. Basic Books.

49. Seymour Papert. 1993. The Children's Machine: Rethinking school in the age of the computer. Basic Books.

50. Seymour Papert. 2006. Digital Development: How the $\$ 100$ Laptop Could Change Education. USINFO Webchat, via OLPC Talks. http://olpctalks.com/ seymour_papert/seymour_papert_usinfo.html

51. Roy Pea. 1987. The Aims of Software Criticism: Reply to Professor Papert. Educational Researcher 16, 5, 4-8.

52. Brett Robinson. 2013. Apple and the religious roots of technological devotion. LA Times.

53. Daniela K. Rosner and Morgan G. Ames. 2014. Designing for Repair? Infrastructures and Materialities of Breakdown. Proc. CSCW 2014, ACM Press.

54. Howard P. Segal. 2005. Technological Utopianism in American Culture. Syracuse Univ. Press.
55. Tim O Shea and Timothy Koschmann. 1997. Review, The Children's Machine: Rethinking School in the Age of the Computer (book). Journal of Learning Sciences 6 , 4, 401-415.

56. William A. Stahl. 1999. God and the Chip: Religion and the Culture of Technology. Wilfrid Laurier Univ. Press.

57. Maria Stavrinaki. 2010. The African Chair or the Charismatic Object. Grey Room 41, 88-110.

58. Douglas Thomas. 2002. Hacker Culture. U. Minnesota Press, Minneapolis, MN.

59. Anna Tsing. 2000. The Global Situation. Cultural Anthropology 15, 3, 327-360.

60.Fred Turner. 2006. How Digital Technology Found Utopian Ideology: Lessons from the first Hackers conference. In Critical Cyberculture Studies: Current terrains, future directions, David Silver, Adrienne Massanari, Steven Jones (eds.). NYU Press.

61.Fred Turner. 2006. From Counterculture to Cyberculture: Stewart Brand, the Whole Earth Network, and the Rise of Digital Utopianism. U. Chicago Press.

62. David Tyack and Larry Cuban. 1995. Tinkering toward Utopia: A Century of Public School Reform. Harvard Univ. Press.

63. Wayan Vota. 2007. Is OLPC the Only Hope to Eliminate Poverty and Create World Peace? OLPC News. http://olpcnews.com/people/negroponte/olpc_poverty_wo rld_peace.html

64. Wayan Vota. 2009. Negroponte Throws XO on Stage Floor "Do this with a Dell" - Everyone a Twitter. OLPC News Forums. http://olpcnews.com/forum/?topic $=4597.0$

65. Wayan Vota. 2010. Mesh Networking Just Doesn't Work on XO-1.5 Laptop. OLPC News. http://olpcnews.com/har dware/wireless/mesh_networking_just_doesnt_wo.html

66. Wayan Vota. 2011. XO Helicopter Deployments? Nicholas Negroponte Must be Crazy! OLPC News. http://olpcnews.com/people/negroponte/xo_helicopter_de ployments_nich.html

67. Mark Warschauer and Morgan G. Ames. 2010. Can One Laptop per Child Save the World's Poor? Journal of International Affairs 64, 1, 33-51.

68. Max Weber. 1947. Charismatic Authority. In The Theory of Social and Economic Organization, Talcott Parsons (ed.). The Free Press.

69.Langdon Winner. 1997. Technology today: Utopia or dystopia? Social Research 64, 3, 989-1017.

70. Geraldine Youcha. 1995. Minding the Children: Child care in America from colonial times to the present. Da Capo Press.

71. Joseph L. Zornado. 2001. Inventing the Child: Culture, Ideology, and the Story of Childhood. Garland Publishing. 